\title{
In vitro effects of somatostatin on the growth hormone-insulin-like growth factor axis in orange-spotted grouper (Epinephelus coioides)
}

Bin Wang, Jirong Jia, Guokun Yang, Jingkai Qin, Cong Zhang, Qiuping Zhang, Caiyun Sun and

\author{
Wensheng $\mathrm{Li}^{*}$
}

State Key Laboratory of Biocontrol, Institute of Aquatic Economic Animals and Guangdong

Province Key Laboratory for Aquatic Economic Animals, School of Life Sciences, Sun Yat-Sen University, Guangzhou 510275, China

Corresponding author: Wensheng $\mathrm{Li}$

Tel/Fax: + 862039332987

E-mail: 1sslws@mail.sysu.edu.cn

Postal address: School of Life Sciences, Sun Yat-Sen University, No. 135 Xingang West Road, Guangzhou, 510275, China

\begin{abstract}
Growth in vertebrates is mainly mediated by the growth hormone (GH)-insulin-like growth factor (IGF) axis, and somatostatin (SRIF) inhibits growth by decreasing GH release at the pituitary level and antagonizing the release and action of GHRH in the hypothalamus. However, the effects of SRIF on the regulation of growth at levels other than GH release from the pituitary gland are less
\end{abstract}


well known. In the present study, we comprehensively examined the pituitary and peripheral actions of SRIF on the GH-IGF axis in grouper using a primary pituitary and hepatocyte cell culture system. Our results showed that SRIF inhibited GH release at the pituitary level, but had no influence on GH mRNA expression. Basal hepatic GH receptor 1 (GHR1), IGF-I and IGF-II mRNA levels declined over time, whereas GHR2 mRNA levels remained stable throughout the culture period. GH stimulated the hepatic expression of GHR and IGF mRNAs in a dose-dependent manner, while SRIF suppressed both basal and GH-stimulated expression of GHR and IGF mRNAs in primary cultured hepatocytes. The inhibition of GHR and IGF mRNA levels by SRIF was not attributed to the rate of mRNA degradation. To the best of our knowledge, we demonstrated the effects of SRIF on basal and GH-stimulated IGF-II mRNA levels in teleosts for the first time. These results indicate that SRIF regulates growth at the level of the pituitary and peripheral liver.

Key words: somatostatin; growth hormone; growth hormone receptor; insulin-like growth factor; grouper; primary cell cultures

\section{Introduction}

The growth of vertebrates, including teleosts, is primarily controlled by the growth hormone (GH)-insulin-like growth factor (IGF) axis. Most research on the regulation of growth has focused on the production and release of GH from the pituitary gland (Canosa et al., 2007; Chang et al., 2012; Gahete et al., 2009; Reindl and Sheridan, 2012; Rousseau and Dufour, 2007; Wong et al., 2006). Moreover, IGF-I, the major mediator of the growth-promoting effects of GH, clearly 
plays an essential role in the growth regulation of vertebrates (Beckman, 2011; Moriyama et al., 2000; Wood et al., 2005). However, the regulation of growth also occurs at levels other than GH production and release, and knowledge of growth control outside the level of the pituitary, such as levels involving GH receptor (GHR) regulation, IGF regulation and IGF receptor regulation by somatostatin, is just emerging in fish (Reindl andSheridan, 2012).

Somatostatin (SS or SST), which is also known as somatotropin release-inhibitory factor (SRIF), is a cyclic 14-amino acid peptide that was originally isolated from ovine hypothalamus and is known for inhibiting the secretion of GH (Brazeau et al., 1973). SRIF participates in growth, development, metabolism and reproductive processes (Klein and Sheridan, 2008; Kumar and Grant, 2010; Rousseau and Dufour, 2007; Sheridan and Kittilson, 2004) via five seven-transmembrane G-protein-coupled receptors (GPCRs). SRIF is well established as the primary inhibitor of $\mathrm{GH}$ release in many species of teleosts and plays a major role in the regulation of growth in fish (Klein and Sheridan, 2008; Sheridan and Hagemeister, 2010; Very and Sheridan, 2002). Recently, it has been shown that SRIF is essential for the sexual dimorphism of GH secretion in mice (Adams et al., 2015). However, the effects of SRIF on GH gene expression are less well understood, and different researchers have obtained contradictory conclusions, even in the same model (e.g., rats) (Ben-Shlomo and Melmed, 2010; Chang et al., 2012; Rousseau and Dufour, 2004; Sheridan and Hagemeister, 2010).

The GH-IGF axis of fish is particularly complex due to a genome duplication that occurred during their evolution, resulting in multiple forms of GH, GHR, and IGF. GH exerts growth-promoting effects in fish and other vertebrates by binding to GHRs, which are most abundant in the liver, and IGF-I, which is principally derived from liver tissue is the primary 
mediator of GH. Numerous hormones and environmental factors have dramatic effects on the expression of the components of the GH-IGF axis, and the regulation appears to be both organismand tissue-specific (Reindl and Sheridan, 2012; Reinecke, 2010). Although various hormones and environmental factors have been reported to play a role in the regulation of the GH-IGF axis in fish, to the best of our knowledge, only one study to date has shown that SRIF decreases hepatic GHR1, GHR2 and IGF-I mRNA levels in rainbow trout (Reindl and Sheridan, 2012).

IGFs (IGF-I and IGF-II) stimulate somatic growth and development in vertebrates. In mammals, IGF-I is regarded as the principal regulator of postnatal growth and is stimulated by GH, while IGF-II regulates placental and fetal growth and is not stimulated by GH (Pierce et al., 2011; Pierce et al., 2010). In bony fish, similar to the widespread presence of the IGF-I gene, IGF-II mRNA has been detected in the liver and other numerous tissues, which is in contrast to IGF-II mRNA expression in mammals (Reinecke et al., 2005). Moreover, GH stimulates both IGF-I and IGF-II in teleosts (Reindl and Sheridan, 2012; Reinecke et al., 2005). In GH-overexpressing tilapia, high expression of GH not only stimulates IGF-I but also IGF-II mRNA in liver and most extrahepatic sites, indicating that IGF-II is also involved in growth regulation (Eppler et al., 2010). These observations suggest that IGF-II may be a somatomedin in fish. However, data regarding the effects of SRIF on IGF-II synthesis and secretion are absent in teleosts.

Orange-spotted grouper (Epinephelus coioides) is an economically important marine fish that is widely cultured in South China and Southeast Asia, and the regulation of its growth is particularly important in aquaculture (Wang et al., 2014). However, grouper is a protogynous hermaphrodite with a low growth rate, as it usually takes 16-24 months to grow to a commercial fish weight of 500 to $750 \mathrm{~g}$ from a juvenile fish with body length of $10 \mathrm{~cm}$. Thus, it is necessary to 
systematically clarify the role of SRIF in regulating the growth of grouper to improve its growth performance. Using the orange-spotted grouper as a model, four SRIF receptors (SSTRs), which could convey SRIF signal transduction, have been characterized, and they are all expressed in the liver of grouper (Haiyan et al., 2010), indicating that SRIF may have direct physiological actions on the hepatocytes. The cDNAs for grouper GH and IGF-I were cloned, and their mRNA expression during the embryonic stages, early larval development stages and different nutritional status were also examined ( $\mathrm{Li}$ et al., 2005; Pedroso et al., 2006). In addition, there are two types of GHRs present in grouper, and they have different structural features and tissues expression patterns ( $\mathrm{Li}$ et al., 2007). Here, we comprehensively examined the pituitary and liver actions of SRIF on the GH-IGF axis in grouper, and our results showed that SRIF regulates growth in both a central (pituitary) and peripheral (liver) manner.

\section{Materials and methods}

\subsection{Animals}

All of the animal experiments were approved by the animal care committee of Sun Yat-sen University. Approximately two-year-old female orange-spotted grouper (Epinephelus coioides) with a body weight of 550 to $650 \mathrm{~g}$ were purchased from the Huangsha aquatic products wholesale market in Guangzhou, China. The fish were acclimated to indoor tanks with recirculating seawater at room temperature under a cyclic light-dark photoperiod (12 h: $12 \mathrm{~h})$ for at least one week. During the acclimation period, the fish were fed commercial pellets daily until satiety as previously described (Wang et al., 2014).

\subsection{Pituitary cell dispersion, culture and treatments}


Pituitary cells were dispersed by the trypsin-DNase method as described previously (Wang et al.,2014). The dispersed pituitary cells were cultured in poly-D-lysine-coated 24-well tissue culture plates (Corning, NY, USA) at a density of $3 \times 10^{5}$ cells/well in $1 \mathrm{~mL}$ of L15 medium (Gibco, supplemented with $1.19 \mathrm{~g} / \mathrm{L}$ HEPES, $2.66 \mathrm{~g} / \mathrm{L}$ sodium chloride, $1 \mathrm{~g} / \mathrm{L}$ bovine serum albumin (BSA), 100,000 U/L penicillin, and $100 \mathrm{mg} / \mathrm{L}$ streptomycin, $\mathrm{pH}$ 7.2) for $2 \mathrm{~h}$ at $25^{\circ} \mathrm{C}$ and saturated humidity with plain air in an incubator. Then, $10 \%$ fetal bovine serum (FBS; Gibco) was added to each well, and the cells were cultured overnight under the same conditions as described above.

On the following day, the medium was removed and the cells were preincubated with fresh L15 medium without FBS for $1 \mathrm{~h}$ to stabilize basal GH secretion before adding various concentrations $(10,100$, and $1000 \mathrm{nM})$ of SRIF (Sigma, USA) and incubated for $24 \mathrm{~h}$. At the end of the incubation period, the medium was removed and centrifuged at $5000 \mathrm{~g}$ at $4^{\circ} \mathrm{C}$ for $5 \mathrm{~min}$, and then, the supernatants were collected and stored at $-80^{\circ} \mathrm{C}$ until $\mathrm{GH}$ release was measured. In addition, $1 \mathrm{~mL}$ of TRIzol reagent (Invitrogen, USA) was added to each well, and the samples were stored at $-80{ }^{\circ} \mathrm{C}$ until RNA extraction. Pituitaries from at least fifteen groupers were pooled for pituitary cell preparation in each experiment and each experiment was repeated twice (separate cell preparations). All treatments were done with six replicate wells in each experiment.

\subsection{Hepatocyte isolation, culture and treatments}

Hepatocyte isolation was performed as described previously (Schmid et al., 2000; Sun et al., 2014), with some modifications. Briefly, the fish were anesthetized with 0.05\% MS222 (Sigma, USA) and sacrificed through decapitation. After decapitation, livers were separated and placed in ice-cold HBSS (calcium-magnesium-phenolred-free D-Hanks supplemented with $10 \mathrm{mM}$ 
HEPES, 5.6 mM D-glucose, 100,000 U/L penicillin, and $100 \mathrm{mg} / \mathrm{L}$ streptomycin, pH 7.5). After being washed three times with HBSS, the livers were minced with scissors and then sliced $(0.5$ mm) using a McIlwain Tissue Chopper (Mickle Laboratory Engineering Co. Ltd, UK). After another three washes, the livers were treated with $1 \mathrm{mM}$ EDTA and then washed three times with HBSS. The tissue were digested with $30 \mathrm{~mL}$ of HBSS supplemented with collagenase IV $(0.5$ $\mathrm{mg} / \mathrm{mL}$, Sigma) and DNase II (13 U/mL, Worthington) for 20 min at $28^{\circ} \mathrm{C}$ with gentle shaking. The fragments were mechanically dispersed using a sterile Pasteur pipet, and the dispersed cells were filtered sequentially through sterile nylon gauze (380- $\mu \mathrm{m}$ mesh, $150-\mu \mathrm{m}$ mesh, and $75-\mu \mathrm{m}$ mesh). Following that, the cells were collected in three different centrifugation steps ( $70 \mathrm{~g}$ for 5 $\mathrm{min}, 50 \mathrm{~g}$ for $5 \mathrm{~min}$, and $30 \mathrm{~g}$ for $5 \mathrm{~min}$ ). The pelleted cells were resuspended in L15 medium, and cell viability and yield were determined using the trypan blue exclusion method.

The dispersed hepatocytes were cultured in collagen (Sigma, USA)-coated 24-well tissue culture plates at a density of $5 \times 10^{5}$ cells/well in $1 \mathrm{~mL}$ of L15 medium with $10 \% \mathrm{FBS}$ at $25^{\circ} \mathrm{C}$ and saturated humidity with plain air in an incubator. After being cultured overnight, the medium was gently changed to serum-free fresh L15 medium and the cell cultures were incubated for $1 \mathrm{~h}$ prior to different treatments as follows: 1) The cell cultures were treated with SRIF at doses ranging from 10 to $1000 \mathrm{nM}$ for 6,12 , and $24 \mathrm{~h}$ to study the effects of SRIF on basal expression of GHR and IGF mRNAs; 2) the cell cultures were further incubated for $0,6,12$, and $24 \mathrm{~h}$ to assess the effects of incubation time on the expression of GHR and IGF mRNAs; 3) the cell cultures were treated with recombinant grouper $\mathrm{GH}(\mathrm{rgGH}$, prepared in our lab) at doses ranging from 1 to $1000 \mathrm{ng} / \mathrm{mL}$ for $12 \mathrm{~h}$ to evaluate the effects of $\mathrm{rgGH}$ on the expression of GHR and IGF mRNAs; 4) the cell cultures were co-incubated with $100 \mathrm{ng} / \mathrm{mL}(4.5 \mathrm{nM}) \mathrm{rgGH}$ and $100 \mathrm{nM}$ SRIF for $12 \mathrm{~h}$ 
to examine the interactions of SRIF with rgGH on the expression of GHR and IGF mRNAs; and 5) the cell cultures were pretreated for $1 \mathrm{~h}$ with actinomycin $\mathrm{D}(5 \mu \mathrm{g} / \mathrm{mL}=4 \mu \mathrm{M})$ and challenged with SRIF (100 nM) for $0,6,12$, and $24 \mathrm{~h}$ to investigate the effects of SRIF on the stability of GHR and IGF mRNAs in primary cultured hepatocytes of grouper (Results see supplementary data). At the end of the incubation, the medium were removed and $1 \mathrm{~mL}$ of TRIzol reagent (Invitrogen, USA) was added to each well. Samples were stored at $-80^{\circ} \mathrm{C}$ until RNA extraction. Livers from at least four groupers were pooled for hepatocyte preparation in each experiment and each experiment was repeated at least twice (separate cell preparations). All treatments were done with four to six replicate wells in each experiment.

\subsection{Western blot analysis of GH release}

There are few commercial fish GH ELISA Kits available, and grouper GH has low homology with its counterpart in mammals (Pedroso et al., 2006). Because the ELISA or RIA methods have not been established in our laboratory, we had to use Western blot for the quantification of GH release in this study. In brief, the protein concentration was quantified and the total protein $(100 \mu \mathrm{g})$ was separated by Tricine-SDS-PAGE and transferred to a nitrocellulose membrane $(0.2$ $\mu \mathrm{m}$, Pall Corporation, USA) by electro-blotting. Because GH is a secreted protein, it is not easy to find a reference standard for normalization. Before being blocked with non-fat dry milk, the membranes were stained by Ponceau S (Sigma, USA) to show that an equal amount of protein was loaded in each well (loading control as indicated in the figure) as described previously (Andreelli et al., 2006; Petrocchi Passeri et al., 2012). The membranes were then washed with phosphate buffered saline (PBS, $137 \mathrm{mM}$ sodiumchloride, $2.7 \mathrm{mM}$ potassium chloride, $10 \mathrm{mM}$ disodium 
hydrogen phosphate, $2 \mathrm{mM}$ potassium dihydrogen phosphate, $\mathrm{pH}$ 7.4) and blocked for $1 \mathrm{~h}$ at room temperature with 5\% (w/v) non-fat dry milk in PBS solution and then incubated with the rabbit polyclonal anti-grouper GH antibody prepared in our lab in PBS solution containing 5\% (w/v) BSA and $0.02 \%(\mathrm{v} / \mathrm{v})$ sodium azide overnight at $4^{\circ} \mathrm{C}$. On the following day, after 3 washes $(10$ min each) with PBS, the membranes were incubated with the HRP-conjugated goat anti-rabbit IgG antibody (Boster, Wuhan, China) in PBS solution containing 5\% (w/v) non-fat dry milk for $1 \mathrm{~h}$ at room temperature. After another 3 washes (10 min each) with PBS, the membranes were visualized using an Enhanced Chemiluminescence (ECL) Detection Kit (Amersham, USA) and the GH bands were quantitated by a densitometry software (Image J 1.45, NIH, USA).

\subsection{RNA extraction, reverse-transcription, and real-time quantitative PCR}

Total RNA was extracted from cells using TRIzol reagent (Invitrogen, USA) according to the manufacturer's instruction. The purity and yield of RNA were assessed by a NanoDrop 2000C spectrophotometer (Thermo Scientific, USA) with 260:280 ratios between 1.8 and 2.0. The integrity of RNA was determined on a $1 \%$ agarose electrophoresis gel with ethidium bromide staining, which showed that RNA was not degraded and used for subsequent cDNA synthesis.

One microgram of total RNA was incubated with RNase-free DNase-I (NEB, USA) at $37^{\circ} \mathrm{C}$ for $10 \mathrm{~min}$ to eliminate contaminating genomic DNA and then treated with $5 \mathrm{mM}$ EDTA at $75^{\circ} \mathrm{C}$ for 10 min to inactivate DNase-I. The first strand cDNA was synthesized with M-MLV Reverse Transcriptase (Invitrogen, USA) according to the manufacturer's protocol. Reverse transcription was performed in a volume of $20 \mu \mathrm{L}$ of the reaction mixture containing $1 \mu \mathrm{L}$ of the dNTPs mix (10 mM each), $1 \mu \mathrm{L}$ of random hexamer primers $(50 \mathrm{ng} / \mu \mathrm{L}), 2 \mu \mathrm{L}$ of dithiothreitol $(0.1 \mathrm{M}), 1 \mu \mathrm{L}$ 
of M-MLV Reverse Transcriptase (200 U/ $\mu \mathrm{L})$, and $4 \mu \mathrm{L}$ of $5 \times \mathrm{RT}$ buffer. Reverse transcription was run for $10 \mathrm{~min}$ at $25^{\circ} \mathrm{C}$, followed by $50 \mathrm{~min}$ at $37^{\circ} \mathrm{C}$, and finally 15 min at $75^{\circ} \mathrm{C}$.

The gene expression levels were determined with real-time quantitative PCR. The primers used in this study were the same as previously described (Sun et al., 2014) and are listed in Table 1. A total of $10 \mu \mathrm{L}$ of the PCR reaction volume contained $5 \mu \mathrm{L}$ of Thunderbird SYBR Green qPCR Mix (TOYOBO, Japan), $0.3 \mu \mathrm{L}$ of forward and reverse primers $(10 \mu \mathrm{M}$ each), $1 \mu \mathrm{L}$ of diluted cDNA templates and $3.4 \mu \mathrm{L}$ of water. Amplification of samples were carried out with the Roche LightCycler 480 Real-time PCR Detection System using the following thermal cycling profiles: $95^{\circ} \mathrm{C}$ for $1 \mathrm{~min}, 40$ cycles of $95^{\circ} \mathrm{C}$ for $15 \mathrm{~s}, 56^{\circ} \mathrm{C}$ for $15 \mathrm{~s}$, and $72^{\circ} \mathrm{C}$ for $30 \mathrm{~s}$. Each sample was run in triplicate. No amplification was observed in non-template reactions (water instead of cDNA) that served as a negative control to confirm that the reagents were not contaminated. The specificity of the primers was evaluated using a melting curve analysis, which showed a signal peak to confirm the specificity of the PCR products. A ten-fold serial dilution of the standards containing the qPCR amplicon were conducted to estimate the PCR efficiency as previously described (Schmittgen and Livak, 2008). The $18 \mathrm{~S}$ gene was used as the internal reference, and the $18 \mathrm{~S}$ levels remained stable between various treatments throughout the study. The relative gene expression levels were normalized to the $18 \mathrm{~S}$ levels and were calculated by the comparative Ct method (Schmittgen and Livak, 2008).

\subsection{Statistical analysis}

All of the experiments were performed at least twice, and all of the treatments in each experiment were tested in quadruplicate or sextuplicate. Quantitative data are presented as the 
mean \pm SEM and were analyzed using one-way ANOVA followed by Duncan's multiple range test using the SPSS version 17.0 software (Chicago, IL, USA). Differences between groups with $\mathrm{p}<$ 0.05 were considered statistically significant.

\section{Results}

\subsection{Effects of SRIF on pituitary GH release and mRNA expression}

As expected, various doses of SRIF significantly inhibited GH release after a 24-h treatment. GH release was markedly decreased by $70 \%$ at $1000 \mathrm{nM}$ SRIF, and the suppression amplitudes of the response to different concentrations of SRIF were similar (Fig. 1A). However, the GH mRNA levels were stable after treatment with different doses of SRIF (Fig. 1B).

\subsection{Effects of SRIF on the basal expression of GHR and IGF mRNAs}

To determine the effects of SRIF on the basal expression of GHR and IGF mRNAs, the dose-response and time course effects of SRIF actions on the expression of GHR and IGF mRNAs were evaluated. Fig. 2 shows that treatment of hepatocytes with various doses of SRIF for $6 \mathrm{~h}$ had slight inhibitory effects on the expression of GHR and IGF mRNAs, while treatment for $12 \mathrm{~h}$ significantly suppressed the expression of GHR and IGF mRNAs. Moreover, SRIF inhibited IGF-I mRNA expression after $24 \mathrm{~h}$ of treatment and had no effects on the expression of the other three genes. To further confirm the effects of incubation time on the basal expression of GHR and IGF mRNAs, isolated hepatocytes were incubated for different periods of time. As shown in Fig. 3, the levels of the GHR1 and IGF-II mRNAs declined sharply within $6 \mathrm{~h}$ and remained depressed over the course of the experiment. The IGF-I mRNA levels gradually decreased over 
time, while the GHR2 mRNA levels increased slightly and remained stable over the culture period.

\subsection{Effects of rgGH on the expression of GHR and IGF mRNAs}

In primary cultured hepatocytes, the effects of recombinant grouper $\mathrm{GH}(\mathrm{rgGH})$ on the expression of GHR and IGF mRNAs were also investigated. As shown in Fig. 4, rgGH stimulated the expression of GHR and IGF mRNAs in a concentration-dependent manner. A significant induction of the GHR1 mRNA levels was observed only at $1000 \mathrm{ng} / \mathrm{mL} \mathrm{rgGH}$, and lower concentrations did not significantly affect the GHR1 mRNA levels (Fig. 4A). In contrast, doses of $\mathrm{rgGH}$ of less than and including $10 \mathrm{ng} / \mathrm{mL}$ were ineffective to stimulate the expression of GHR2, IGF-I, and IGF-II mRNAs, while doses of $100 \mathrm{ng} / \mathrm{mL}$ and above progressively stimulated the expression of GHR2, IGF-I, and IGF-II mRNAs and reached maximal levels at $1000 \mathrm{ng} / \mathrm{mL}$ (Figs. 4, B-D). It should be noted that the magnitudes of GHR2 and IGF-II responses to $\operatorname{rgGH}$ were stronger than those of GHR1 and IGF-I, respectively.

\subsection{Effects of SRIF on rgGH-stimulated expression of GHR and IGF mRNAs}

The interplay of SRIF with rgGH on the expression of GHR and IGF mRNAs was evaluated

(Fig. 5). As described above, $\mathrm{rgGH}(100 \mathrm{ng} / \mathrm{mL}=4.5 \mathrm{nM})$ had slight effects on the GHR1 mRNA levels, while rgGH elicited a evident increase of GHR2, IGF-I and IGF-II mRNA expression. Co-incubation of SRIF (100 nM) with rgGH slightly reduced GHR1 mRNA levels versus rgGH alone, whereas significantly reduced increase of the GHR2, IGF-I and IGF-II mRNA levels induced by rgGH. 


\section{Discussion}

In the current study, we investigated the actions of SRIF on the GH-IGF axis and showed that SRIF acted both centrally (pituitary level) and peripherally to regulate growth by inhibiting pituitary GH release. In addition, SRIF reduced both basal and GH-stimulated expression of GHR and IGF mRNAs. However, SRIF did not alter the pituitary GH mRNA levels. To the best of our knowledge, these results demonstrate the effects of SRIF on the basal and GH-induced IGF-II mRNA levels in teleost for the first time. These findings extend our knowledge of the roles of SRIF on the GH-IGF axis and on growth regulation in fish.

SRIF is usually regarded as the major inhibitor of GH release from fish to mammals. However, studies in pigs and baboons have shown that very low, picomolar doses of SRIF markedly stimulate GH release in vitro, which indicates that SRIF is a pleiotropic neuroendocrine factor and not only an inhibitor of GH release (Castano et al., 2005; Cordoba-Chacon et al., 2012). Moreover, catfish SRIF22 and salmonid SRIF25 appear not to have GH secretotropic effects (Very and Sheridan, 2002). Considerable research on the regulation of growth has focused on pituitary GH release, and the mechanisms of SRIF on GH release have been extensively investigated (Anderson et al., 2004; Ben-Shlomo and Melmed, 2010; Canosa et al., 2007; Castano et al., 2005; Chang et al., 2012; Wong et al., 2006). However, data on the effect of SRIF on GH gene expression are limited and conflicting. In fish, there are only three reports demonstrating that SRIF is ineffective in altering basal GH mRNA expression in rainbow trout, tilapia, and goldfish (Chang et al., 2012; Melamed et al., 1996; Yada and Hirano, 1992). In contrast, SRIF suppresses GH gene expression in European eel and grass carp (Li et al., 2000; Rousseau and Dufour, 2004). Interestingly, $\left[\mathrm{Pro}^{2}\right] \mathrm{SRIF} 14$, an isoform of SRIF that is derived from preprosomatostatin III (PSS 
III), elevates basal GH mRNA levels but inhibits GH secretion in goldfish (Chang et al., 2012; Yunker et al., 2003). Likewise, contradicting results appear in mammals, even within the same species (Ben-Shlomo and Melmed, 2010). Such disparate results possibly stem from species-specific differences in the regulation of GH mRNA expression or different experimental parameters, such as doses of SRIF, time of treatment, and experimental methods (in vivo vs. in vitro). In grouper, no change in GH mRNA expression was observed, whereas GH release was suppressed by SRIF (Fig. 1). These results suggest that SRIF operates at the levels of GH synthesis and secretion and not at the GH transcription level, as confirmed by the decrease in total GH in grouper (Wang et al., 2014) and the reduction of total GH in rainbow trout (Yada and Hirano, 1992). However, the mechanisms of the posttranscriptional regulation of GH synthesis by SRIF remain to be clarified.

Our previous study has reported that four SSTR subtypes are highly expressed in the liver of grouper (Haiyan et al., 2010), which indicates that SRIF could act peripherally on the GH-IGF axis at the level of hepatocytes. Consistent with this hypothesis, SRIF reduced both the basal and GH-stimulated levels of GHR and IGF mRNAs in grouper liver (Figs. 2 and 5). The responses of the GHR1 and GHR2 mRNA levels to SRIF were similar, while IGF-I and IGF-II mRNA expression were differentially regulated by SRIF in grouper (Fig. 2). GH increased the expression of GHR2, IGF-I and IGF-II mRNAs, while SRIF reduced the actions of GH (Fig. 5). Likewise, SRIF inhibited the basal GHR1 and GHR2 mRNA levels (Very and Sheridan, 2007) and suppressed both basal and GH-induced expression of IGF-I mRNAs in rainbow trout liver in vitro (Very et al., 2008). Conversely, the basal IGF-I mRNA levels were unaffected by SRIF in isolated rat hepatocytes, but SRIF inhibited the GH-induced IGF-I mRNA levels (Murray et al., 
2004). Additionally, SRIF prevented both basal and GH-induced IGF-I release in rat and rainbow trout (Murray et al., 2004; Very et al., 2008). These observations suggest that the effects of SRIF on the elements of the GH-IGF axis appear to be species-specific and that SRIF suppresses the GH-IGF axis by inhibiting both basal and GH-induced hepatic GHR and IGF production in addition to reducing GH release at the pituitary level.

During the time-course study, GHR1, IGF-I and IGF-II gene expression declined over time, while the GHR2 mRNA levels stayed relatively constant (Fig. 3). Consistent with previous reports, the basal GHR1 mRNA levels decreased rapidly over time, while the basal GHR2 mRNA levels changed little over time in primary cultured tilapia hepatocytes (Pierce et al., 2012). A decline in the basal IGF-I mRNA levels over time was also observed in tilapia, salmon and rainbow trout primary cultured hepatocytes in vitro (Pierce et al., 2011; Pierce et al., 2004; Schmid et al., 2000; Very et al., 2008). However, the IGF-I mRNA levels remained stable over time in isolated rat hepatocytes (Murray et al., 2004). Similarly, the gene expression levels of IGF-II decreased rapidly in tilapia liver in vitro (Pierce et al., 2011). It should be noted that the levels of the $18 \mathrm{~S}$ internal reference did not change over time throughout the study, indicating that the decrease in the expression of GHR1, IGF-I and IGF-II mRNAs were specific, which is consistent with other studies in various teleosts (Pierce et al., 2011; Pierce et al., 2012; Pierce et al., 2004; Schmid et al., 2000; Very et al., 2008).

Differential regulation of GHR and IGF mRNAs by GH were observed in several species. GH stimulated the levels of both GHR and IGF mRNAs in grouper primary hepatocytes in a dose-dependent manner (Fig. 4). GH treatment, with the exception of the $1000 \mathrm{ng} / \mathrm{mL}$ concentration, had little effects on the GHR1 mRNA levels, while doses of $100 \mathrm{ng} / \mathrm{mL}$ and above 
progressively stimulated the expression of GHR2 mRNA. Similarly, the response of the GHR2 mRNA levels to GH was concentration-dependent and biphasic in tilapia liver in vitro, while the GHR1 mRNA levels did not respond to GH (Pierce et al., 2012). However, in vivo administration of seabream with GH did not alter hepatic GHR1 or GHR2 mRNA expression (Jiao et al., 2006). In contrast, down-regulation of GHR by the injection of GH was noted in tilapia liver (Shved et al., 2011). The stimulatory effects of GH on hepatic IGF-I expression are consistent with previous reports in various species of fish, including common carp, rainbow trout, tilapia, seabream and salmon (Leung et al., 2008; Pierce et al., 2011; Pierce et al., 2004; Schmid et al., 2000; Shamblott et al., 1995; Shved et al., 2011; Tse et al., 2002; Very et al., 2008; Vong et al., 2003), as well as mammals (Murray et al., 2004). Additionally, in GH-overexpressing tilapia, IGF-I mRNA expression and peptide levels were strongly elevated in liver (Eppler et al., 2007). In mammals, postnatal growth is regulated almost exclusively by IGF-I, which is secreted from liver under GH stimulation, while IGF-II regulates placental and fetal growth and is not regulated by GH (Reinecke et al., 2005; Reinecke and Collet, 1998; White et al., 2009). Conversely, IGF-II mRNA expression is also up-regulated by GH in bony fish (Pierce et al., 2011; Pierce et al., 2010; Shamblott et al., 1995; Shved et al., 2011; Tse et al., 2002; Vong et al., 2003), implying that IGF-II may fundamentally differ between fish and mammals and that IGF-II appears to be a somatomedin in teleosts (Eppler et al., 2010; Pierce et al., 2010). The differential regulation of the expression of GHR and IGF mRNAs by GH show that these genes appear to mediate different physiological functions in both an organism- and tissue-specific manner.

SRIF inhibited the expression of GHR and IGF mRNAs in primary cultured grouper hepatocytes. As confirmed by decay curves, the inhibitory effects of SRIF on the levels of GHR 
and IGF mRNAs resulted not from altered mRNA degradation but perhaps from reduced mRNA transcription rates (Fig. S1). In the only comparable fish study in rainbow trout, SRIF inhibited the GHR1 and GHR2 mRNA levels by decreasing the transcription of GHR mRNAs (Very and Sheridan, 2007). Similarly, the inhibition of the IGF-I mRNA levels by SRIF resulted from reduced IGF-I mRNA transcription and not from altered mRNA stability (Very et al., 2008).

\section{Conclusion}

In the present study, our results showed that SRIF suppressed the GH-IGF axis in both a central (pituitary) and peripheral (liver) manner. SRIF inhibited pituitary GH release, while it had no effect on GH mRNA expression. SRIF reduced both basal and GH-induced expression of GHR and IGF mRNAs in isolated hepatocytes of grouper. The inhibitory effects of SRIF on the levels of GHR and IGF mRNAs were not a result of altered mRNA stability. The effects of SRIF on the expression of IGF-II mRNA extends our knowledge of the roles of SRIF on the regulation of growth in fish. The mechanisms of posttranscriptional regulation of GH synthesis by SRIF and the mechanisms mediating the actions of SRIF on IGF-II mRNA expression await further study.

\section{Acknowledgements}

This work was supported by the National Science Foundation of China (31472259, 31272639), the National Basic Research Program (973 program, 2004CB117402, 2010CB126302), the Guangdong Provincial Science and Technology Program (2015A020216006) and a grant from the Fundamental Research Funds for the Central Universities to Dr. Wensheng Li.

\section{References}

Adams, J.M., Otero-Corchon, V., Hammond, G.L., Veldhuis, J.D., Qi, N., Low, M.J., 2015. Somatostatin is essential for the sexual dimorphism of $\mathrm{GH}$ secretion, corticosteroid-binding globulin production, and corticosterone levels in mice. Endocrinology 156, 1052-1065.

Anderson, L.L., Jeftinija, S., Scanes, C.G., 2004. Growth hormone secretion: molecular and cellular 
mechanisms and in vivo approaches. Exp. Biol. Med. (Maywood) 229, 291-302.

Andreelli, F., Foretz, M., Knauf, C., Cani, P.D., Perrin, C., Iglesias, M.A., Pillot, B., Bado, A., Tronche, F., Mithieux, G., Vaulont, S., Burcelin, R., Viollet, B., 2006. Liver adenosine monophosphate-activated kinase-alpha2 catalytic subunit is a key target for the control of hepatic glucose production by adiponectin and leptin but not insulin. Endocrinology 147, 2432-2441.

Beckman, B.R., 2011. Perspectives on concordant and discordant relations between insulin-like growth factor 1 (IGF1) and growth in fishes. General and comparative endocrinology 170, 233-252.

Ben-Shlomo, A., Melmed, S., 2010. Pituitary somatostatin receptor signaling. Trends Endocrinol. Metab. 21, 123-133.

Brazeau, P., Vale, W., Burgus, R., Ling, N., Butcher, M., Rivier, J., Guillemin, R., 1973. Hypothalamic polypeptide that inhibits the secretion of immunoreactive pituitary growth hormone. Science 179, 77-79.

Canosa, L.F., Chang, J.P., Peter, R.E., 2007. Neuroendocrine control of growth hormone in fish. General and comparative endocrinology 151, 1-26.

Castano, J.P., Delgado-Niebla, E., Duran-Prado, M., Luque, R.M., Sanchez-Hormigo, A., Gracia-Navarro, F., Garcia-Navarro, S., Kineman, R.D., Malagon, M.M., 2005. New insights in the mechanism by which SRIF influences GH secretion. J. Endocrinol. Invest. 28, 10-13.

Chang, J.P., Habibi, H.R., Yu, Y., Moussavi, M., Grey, C.L., Pemberton, J.G., 2012. Calcium and other signalling pathways in neuroendocrine regulation of somatotroph functions. Cell Calcium 51, 240-252.

Cordoba-Chacon, J., Gahete, M.D., Culler, M.D., Castano, J.P., Kineman, R.D., Luque, R.M., 2012. Somatostatin dramatically stimulates growth hormone release from primate somatotropes acting at low doses via sst5 and cAMP. J. Neuroendocrinol. 24, 453-463.

Eppler, E., Berishvili, G., Mazel, P., Caelers, A., Hwang, G., Maclean, N., Reinecke, M., 2010. Distinct organ-specific up- and down-regulation of IGF-I and IGF-II mRNA in various organs of a GH-overexpressing transgenic Nile tilapia. Transgenic Res. 19, 231-240.

Eppler, E., Caelers, A., Shved, N., Hwang, G., Rahman, A.M., Maclean, N., Zapf, J., Reinecke, M., 2007. Insulin-like growth factor I (IGF-I) in a growth-enhanced transgenic (GH-overexpressing) bony fish, the tilapia (Oreochromis niloticus): indication for a higher impact of autocrine/paracrine than of endocrine IGF-I. Transgenic Res. 16, 479-489.

Gahete, M.D., Duran-Prado, M., Luque, R.M., Martinez-Fuentes, A.J., Quintero, A., Gutierrez-Pascual, E., Cordoba-Chacon, J., Malagon, M.M., Gracia-Navarro, F., Castano, J.P., 2009. Understanding the multifactorial control of growth hormone release by somatotropes: lessons from comparative endocrinology. Ann. N. Y. Acad. Sci. 1163, 137-153.

Haiyan, D., Wensheng, L., Haoran, L., 2010. Comparative analyses of sequence structure, evolution, and expression of four somatostatin receptors in orange-spotted grouper (Epinephelus coioides). Mol. Cell. Endocrinol. 323, 125-136.

Jiao, B., Huang, X., Chan, C.B., Zhang, L., Wang, D., Cheng, C.H., 2006. The co-existence of two growth hormone receptors in teleost fish and their differential signal transduction, tissue distribution and hormonal regulation of expression in seabream. J. Mol. Endocrinol. 36, 23-40.

Klein, S.E., Sheridan, M.A., 2008. Somatostatin signaling and the regulation of growth and metabolism in fish. Mol. Cell. Endocrinol. 286, 148-154.

Kumar, U., Grant, M., 2010. Somatostatin and somatostatin receptors. Results Probl. Cell Differ. 50, 137-184.

Leung, L.Y., Kwong, A.K., Man, A.K., Woo, N.Y., 2008. Direct actions of cortisol, thyroxine and growth 
hormone on IGF-I mRNA expression in sea bream hepatocytes. Comp. Biochem. Physiol. A Mol. Integr. Physiol. 151, 705-710.

Li, W.S., Chen, D., Wong, A.O., Lin, H.R., 2005. Molecular cloning, tissue distribution, and ontogeny of mRNA expression of growth hormone in orange-spotted grouper (Epinephelus coioides). General and comparative endocrinology 144, 78-89.

Li, W.S., Chu, M.M.S., Lin, H.R., Wong, A.O.L., 2000. Interactions of pituitary adenylate cyclase activating polypeptide with gonadotropin-releasing hormone, dopamine, and somatostatin in regulating growth hormone gene expression in grass carp pituitary cells. Presented at the Fourth International Symposium on Fish Endocrinology, Seattle, WA, July 31-August 3, 2000.

Li, Y., Liu, X., Zhang, Y., Zhu, P., Lin, H., 2007. Molecular cloning, characterization and distribution of two types of growth hormone receptor in orange-spotted grouper (Epinephelus coioides). General and comparative endocrinology 152, 111-122.

Melamed, P., Gur, G., Elizur, A., Rosenfeld, H., Sivan, B., Rentier-Delrue, F., Yaron, Z., 1996. Differential effects of gonadotropin-releasing hormone, dopamine and somatostatin and their second messengers on the mRNA levels of gonadotropin II beta subunit and growth hormone in the teleost fish, tilapia. Neuroendocrinology 64, 320-328.

Moriyama, S., Ayson, F.G., Kawauchi, H., 2000. Growth regulation by insulin-like growth factor-I in fish. Biosci. Biotechnol. Biochem. 64, 1553-1562.

Murray, R.D., Kim, K., Ren, S.G., Chelly, M., Umehara, Y., Melmed, S., 2004. Central and peripheral actions of somatostatin on the growth hormone-IGF-I axis. J. Clin. Invest. 114, 349-356.

Pedroso, F.L., de Jesus-Ayson, E.G., Cortado, H.H., Hyodo, S., Ayson, F.G., 2006. Changes in mRNA expression of grouper (Epinephelus coioides) growth hormone and insulin-like growth factor I in response to nutritional status. General and comparative endocrinology 145, 237-246.

Petrocchi Passeri, P., Biondini, L., Mongiardi, M.P., Mordini, N., Quaresima, S., Frank, C., Baratta, M., Bartolomucci, A., Levi, A., Severini, C., Possenti, R., 2012. Neuropeptide TLQP-21, a VGF Internal Fragment, Modulates Hormonal Gene Expression and Secretion in GH3 Cell Line. Neuroendocrinology. Pierce, A.L., Breves, J.P., Moriyama, S., Hirano, T., Grau, E.G., 2011. Differential regulation of Igf1 and Igf2 mRNA levels in tilapia hepatocytes: effects of insulin and cortisol on GH sensitivity. J. Endocrinol. 211, 201-210.

Pierce, A.L., Breves, J.P., Moriyama, S., Uchida, K., Grau, E.G., 2012. Regulation of growth hormone (GH) receptor (GHR1 and GHR2) mRNA level by GH and metabolic hormones in primary cultured tilapia hepatocytes. General and comparative endocrinology 179, 22-29.

Pierce, A.L., Dickey, J.T., Felli, L., Swanson, P., Dickhoff, W.W., 2010. Metabolic hormones regulate basal and growth hormone-dependent igf2 mRNA level in primary cultured coho salmon hepatocytes: effects of insulin, glucagon, dexamethasone, and triiodothyronine. J. Endocrinol. 204, 331-339.

Pierce, A.L., Dickey, J.T., Larsen, D.A., Fukada, H., Swanson, P., Dickhoff, W.W., 2004. A quantitative real-time RT-PCR assay for salmon IGF-I mRNA, and its application in the study of GH regulation of IGF-I gene expression in primary culture of salmon hepatocytes. General and comparative endocrinology 135, 401-411.

Reindl, K.M., Sheridan, M.A., 2012. Peripheral regulation of the growth hormone-insulin-like growth factor system in fish and other vertebrates. Comp. Biochem. Physiol. A Mol. Integr. Physiol. 163, 231-245.

Reinecke, M., 2010. Influences of the environment on the endocrine and paracrine fish growth hormone-insulin-like growth factor-I system. J. Fish Biol. 76, 1233-1254. 
Reinecke, M., Bjornsson, B.T., Dickhoff, W.W., McCormick, S.D., Navarro, I., Power, D.M., Gutierrez, J., 2005. Growth hormone and insulin-like growth factors in fish: where we are and where to go. General and comparative endocrinology 142, 20-24.

Reinecke, M., Collet, C., 1998. The phylogeny of the insulin-like growth factors. Int. Rev. Cytol. 183, 1-94.

Rousseau, K., Dufour, S., 2004. Phylogenetic evolution of the neuroendocrine control of growth hormone: contribution from teleosts. Cybium 28, 181-198.

Rousseau, K., Dufour, S., 2007. Comparative aspects of GH and metabolic regulation in lower vertebrates. Neuroendocrinology 86, 165-174.

Schmid, A.C., Reinecke, M., Kloas, W., 2000. Primary cultured hepatocytes of the bony fish, Oreochromis mossambicus, the tilapia: a valid tool for physiological studies on IGF-I expression in liver. J. Endocrinol. 166, 265-273.

Schmittgen, T.D., Livak, K.J., 2008. Analyzing real-time PCR data by the comparative C(T) method. Nat. Protoc. 3, 1101-1108.

Shamblott, M.J., Cheng, C.M., Bolt, D., Chen, T.T., 1995. Appearance of insulin-like growth factor mRNA in the liver and pyloric ceca of a teleost in response to exogenous growth hormone. Proc. Natl. Acad. Sci. U. S. A. 92, 6943-6946.

Sheridan, M.A., Hagemeister, A.L., 2010. Somatostatin and somatostatin receptors in fish growth. General and comparative endocrinology 167, 360-365.

Sheridan, M.A., Kittilson, J.D., 2004. The role of somatostatins in the regulation of metabolism in fish. Comp. Biochem. Physiol. B Biochem. Mol. Biol. 138, 323-330.

Shved, N., Berishvili, G., Mazel, P., Baroiller, J.F., Eppler, E., 2011. Growth hormone (GH) treatment acts on the endocrine and autocrine/paracrine GH/IGF-axis and on TNF-alpha expression in bony fish pituitary and immune organs. Fish \& shellfish immunology 31, 944-952.

Sun, C., Duan, D., Li, B., Qin, C., Jia, J., Wang, B., Dong, H., Li, W., 2014. UII and UT in grouper: cloning and effects on transcription of hormones related to growth control. J. Endocrinol. 220, 35-48.

Tse, M.C., Vong, Q.P., Cheng, C.H., Chan, K.M., 2002. PCR-cloning and gene expression studies in common carp (Cyprinus carpio) insulin-like growth factor-II. Biochim. Biophys. Acta 1575, 63-74.

Very, N.M., Kittilson, J.D., Klein, S.E., Sheridan, M.A., 2008. Somatostatin inhibits basal and growth hormone-stimulated hepatic insulin-like growth factor-I production. Mol. Cell. Endocrinol. 281, 19-26.

Very, N.M., Sheridan, M.A., 2002. The role of somatostatins in the regulation of growth in fish. Fish physiology and biochemistry 27, 217-226.

Very, N.M., Sheridan, M.A., 2007. Somatostatin regulates hepatic growth hormone sensitivity by internalizing growth hormone receptors and by decreasing transcription of growth hormone receptor mRNAs. Am. J. Physiol. Regul. Integr. Comp. Physiol. 292, R1956-1962.

Vong, Q.P., Chan, K.M., Cheng, C.H., 2003. Quantification of common carp (Cyprinus carpio) IGF-I and IGF-II mRNA by real-time PCR: differential regulation of expression by GH. J. Endocrinol. 178, 513-521. Wang, B., Qin, C., Zhang, C., Jia, J., Sun, C., Li, W., 2014. Differential involvement of signaling pathways in the regulation of growth hormone release by somatostatin and growth hormone-releasing hormone in orange-spotted grouper (Epinephelus coioides). Mol. Cell. Endocrinol. 382, 851-859.

White, Y.A., Kyle, J.T., Wood, A.W., 2009. Targeted gene knockdown in zebrafish reveals distinct intraembryonic functions for insulin-like growth factor II signaling. Endocrinology 150, 4366-4375.

Wong, A.O., Zhou, H., Jiang, Y., Ko, W.K., 2006. Feedback regulation of growth hormone synthesis and secretion in fish and the emerging concept of intrapituitary feedback loop. Comp. Biochem. Physiol. A 
Mol. Integr. Physiol. 144, 284-305.

Wood, A.W., Duan, C., Bern, H.A., 2005. Insulin-like growth factor signaling in fish. Int. Rev. Cytol. 243, 215-285.

Yada, T., Hirano, T., 1992. Inhibition of growth hormone synthesis by somatostatin in cultured pituitary of rainbow trout. Journal of Comparative Physiology B 162, 575-580.

Yunker, W.K., Smith, S., Graves, C., Davis, P.J., Unniappan, S., Rivier, J.E., Peter, R.E., Chang, J.P., 2003. Endogenous hypothalamic somatostatins differentially regulate growth hormone secretion from goldfish pituitary somatotropes in vitro. Endocrinology 144, 4031-4041.

\section{Table and Figure Legends}

Table 1. Information of primers used in real-timePCR

Fig. 1. Effects of SRIF on GH release and mRNA expression in primary cultured pituitary cells of grouper. After being cultured overnight in L15 medium with 10\% FBS, the pituitary cells were equilibrated for $1 \mathrm{~h}$ in serum-free L15 medium and then incubated for $24 \mathrm{~h}$ with SRIF at doses ranging from 10 to $1000 \mathrm{nM}$. GH release and the mRNA levels were evaluated as described in the Materials and methods. The ponceau S-stained protein band is presented as a loading control to verify uniformity of protein load/transfer. Data are expressed as a percentage of the control and presented as the mean \pm SEM ( $n=6$ wells/treatment/experiment). The asterisk denotes significant differences compared with the control group ( $\mathrm{p}<0.05$; ANOVA followed by Duncan's multiple range test).

Fig. 2. Effects of treatment for 6,12 and $24 \mathrm{~h}$ with different concentrations of SRIF on the expression of GHR1 (A), GHR2 (B), IGF-I (C), and IGF-II (D) mRNAs in primary cultured hepatocytes of grouper. After being cultured overnight in L15 medium with $10 \%$ FBS, hepatocytes were equilibrated for $1 \mathrm{~h}$ in serum-free L15 medium and then incubated for 6, 12, and $24 \mathrm{~h}$ with SRIF at doses ranging from 10 to $1000 \mathrm{nM}$. Data are expressed as a percentage of the corresponding control and presented as the mean \pm SEM 
( $\mathrm{n}=4-6$ wells/treatment/experiment). The asterisk denotes significant differences compared with the corresponding control group ( $\mathrm{p}<0.05$;ANOVA followed by Duncan's multiple range test).

Fig. 3. Effects of incubation time on the expression of GHR1 (A), GHR2 (B), IGF-I (C), and IGF-II (D) mRNAs in primary cultured hepatocytes of grouper. After being cultured overnight in L15 medium with 10\% FBS, hepatocytes were equilibrated for $1 \mathrm{~h}$ in serum-free L15 medium and then incubated further for $0,6,12,24 \mathrm{~h}$ without any treatment. Data are expressed as a percentage of the time 0 control and presented as the mean \pm SEM (n=4-6 wells/treatment/experiment). Groups with different letters are significantly differentfrom each other ( $\mathrm{p}<0.05$;ANOVA followed by Duncan's multiple range test).

Fig. 4. Dose-response study of recombinant grouper GH (rgGH) on the expression of GHR1 (A), GHR2 (B), IGF-I (C), and IGF-II (D) mRNAs in primary cultured hepatocytes of grouper. After being cultured overnight in L15 medium with 10\% FBS, hepatocytes were equilibrated for $1 \mathrm{~h}$ in serum-free L15 medium and then incubated for $12 \mathrm{~h}$ with $\mathrm{rgGH}$ at doses ranging from 1 to $1000 \mathrm{ng} / \mathrm{mL}$. Data are expressed as a percentage of the control and presented as the mean \pm SEM ( $\mathrm{n}=4$ wells/treatment/experiment). Groups with different letters are significantly different from each other ( $\mathrm{p}<0.05$;ANOVA followed by Duncan's multiple range test).

Fig. 5. Effects of SRIF on GH-induced expression of GHR1 (A), GHR2 (B), IGF-I (C), and IGF-II (D) mRNAs in primary cultured hepatocytes of grouper. After being cultured overnight in L15 medium with 10\% FBS, hepatocytes were equilibrated for $1 \mathrm{~h}$ in 
serum-free L15 medium and then incubated for $12 \mathrm{~h}$ with vehicle or $\mathrm{GH}(100 \mathrm{ng} / \mathrm{ml})$ in the absence and presence of SRIF (100 nM). Data are expressed as a percentage of the control and presented as the mean \pm SEM ( $n=4-6$ wells/treatment/experiment). Groups with different letters are significantly different from each other ( $\mathrm{p}<0.05$;ANOVA followed by Duncan's multiple range test). 


\begin{tabular}{|c|c|c|c|c|}
\hline Name & Primer sequence ( $\left.5^{\prime}-3^{\prime}\right)$ & Amplicon size ( bp ) & $\begin{array}{c}\text { PCR } \\
\text { efficiency }\end{array}$ & $\begin{array}{c}\text { GenBank } \\
\text { accession No. }\end{array}$ \\
\hline $18 \mathrm{~S} \mathrm{~F}$ & CCTGAGAAACGGCTACCACATCC & \multirow[t]{2}{*}{221} & \multirow[t]{2}{*}{2.027} & \multirow[t]{2}{*}{ JN603833 } \\
\hline $18 \mathrm{~S} R$ & AGCAATTTGTATACGCTATTGGAG & & & \\
\hline GH F & AGACGGAGGAGCAGCGACAG & \multirow[t]{2}{*}{151} & \multirow[t]{2}{*}{1.996} & \multirow[t]{2}{*}{ AF376771 } \\
\hline GH R & TCCCAGGACTCCACCAACC & & & \\
\hline GHR1 F & GCGACTCCATCTTCATTCA & \multirow[t]{2}{*}{331} & \multirow[t]{2}{*}{1.975} & \multirow[t]{2}{*}{ EF052273 } \\
\hline GHR1 R & GCATCCTCAGCATCCACC & & & \\
\hline GHR2 F & GACGCTGCTGAATGTGA & \multirow[t]{2}{*}{219} & \multirow[t]{2}{*}{1.936} & \multirow[t]{2}{*}{ EF052274 } \\
\hline GHR2 R & ACCCGAACCTCGTGAATG & & & \\
\hline IGF-I F & GTTTGTGTGTGGAGAGAGAGGCT & \multirow[t]{2}{*}{291} & \multirow[t]{2}{*}{2.093} & \multirow[t]{2}{*}{ AY513719 } \\
\hline IGF-I R & СTCTTCTTGTTTTTTGTCTTGTC & & & \\
\hline IGF-II F & ACCCCGCAAAGATACGGACACCAC & \multirow[t]{2}{*}{291} & \multirow[t]{2}{*}{2.015} & \multirow[t]{2}{*}{ AY552787 } \\
\hline IGF-II R & ACGGAAACAACACTCCTCTACGA & & & \\
\hline
\end{tabular}


Figure 1
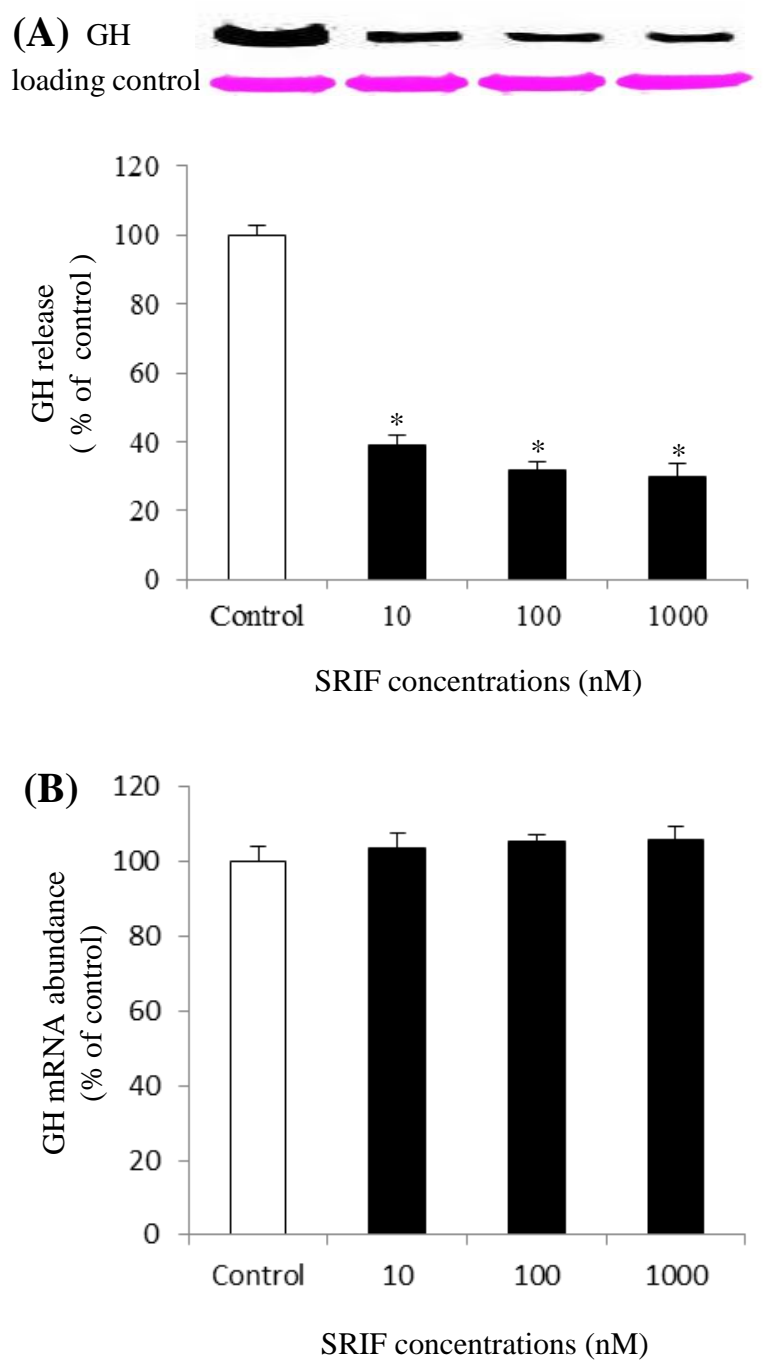
Figure 2

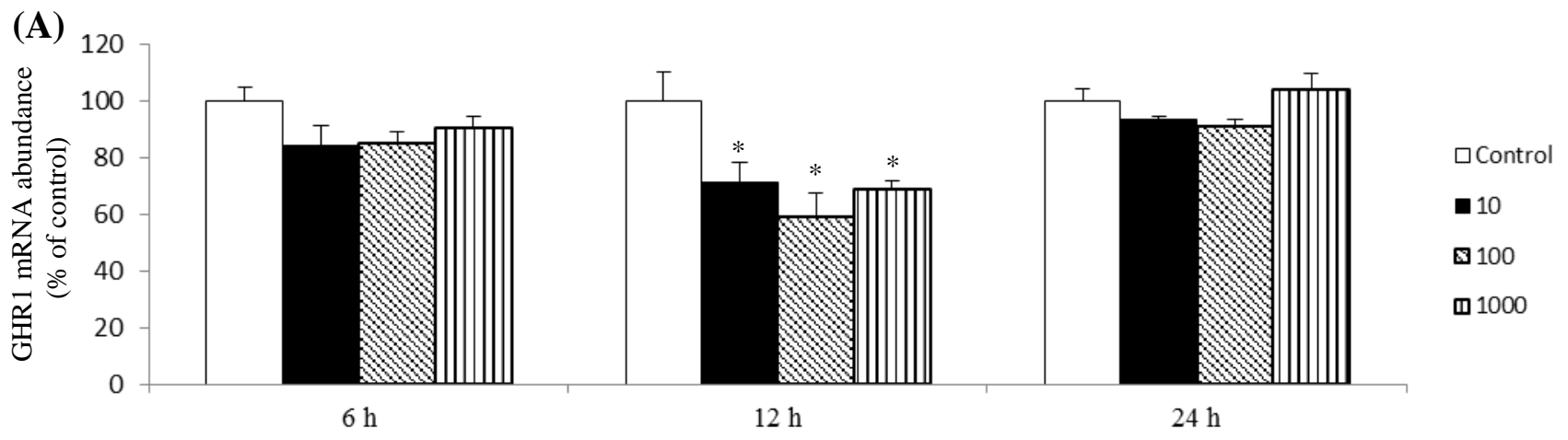

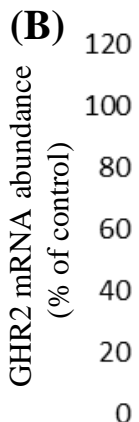

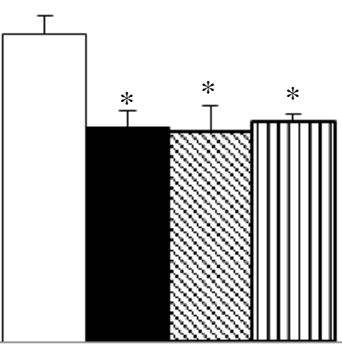

$12 \mathrm{~h}$

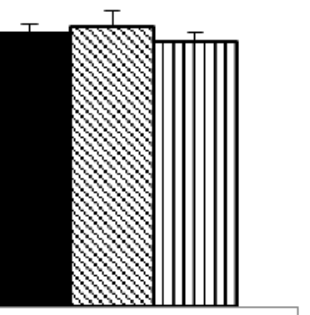

$24 \mathrm{~h}$

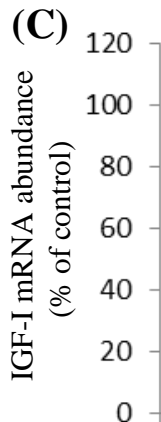

$6 \mathrm{~h}$

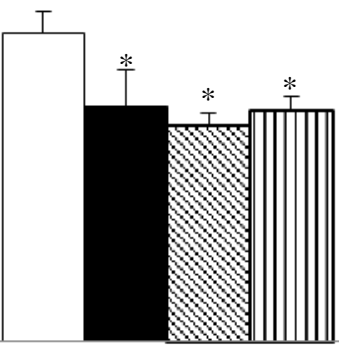

$12 \mathrm{~h}$ $\square$ Control

- 10

\$100

ㅁ 1000

$\square$ Control

- 10

ه 100

प1000

(D)

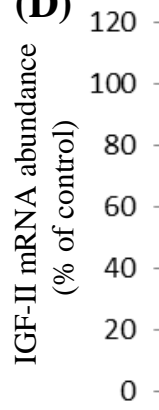

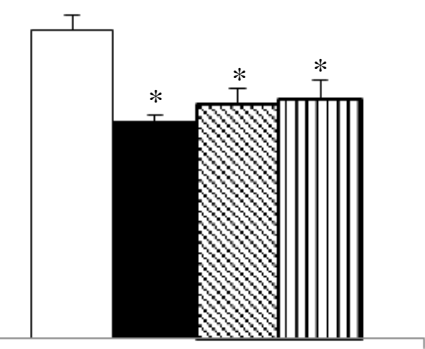

$24 \mathrm{~h}$ $\square$ Control

- 10

ब 100

ㅁ 1000 


\section{Figure 3}
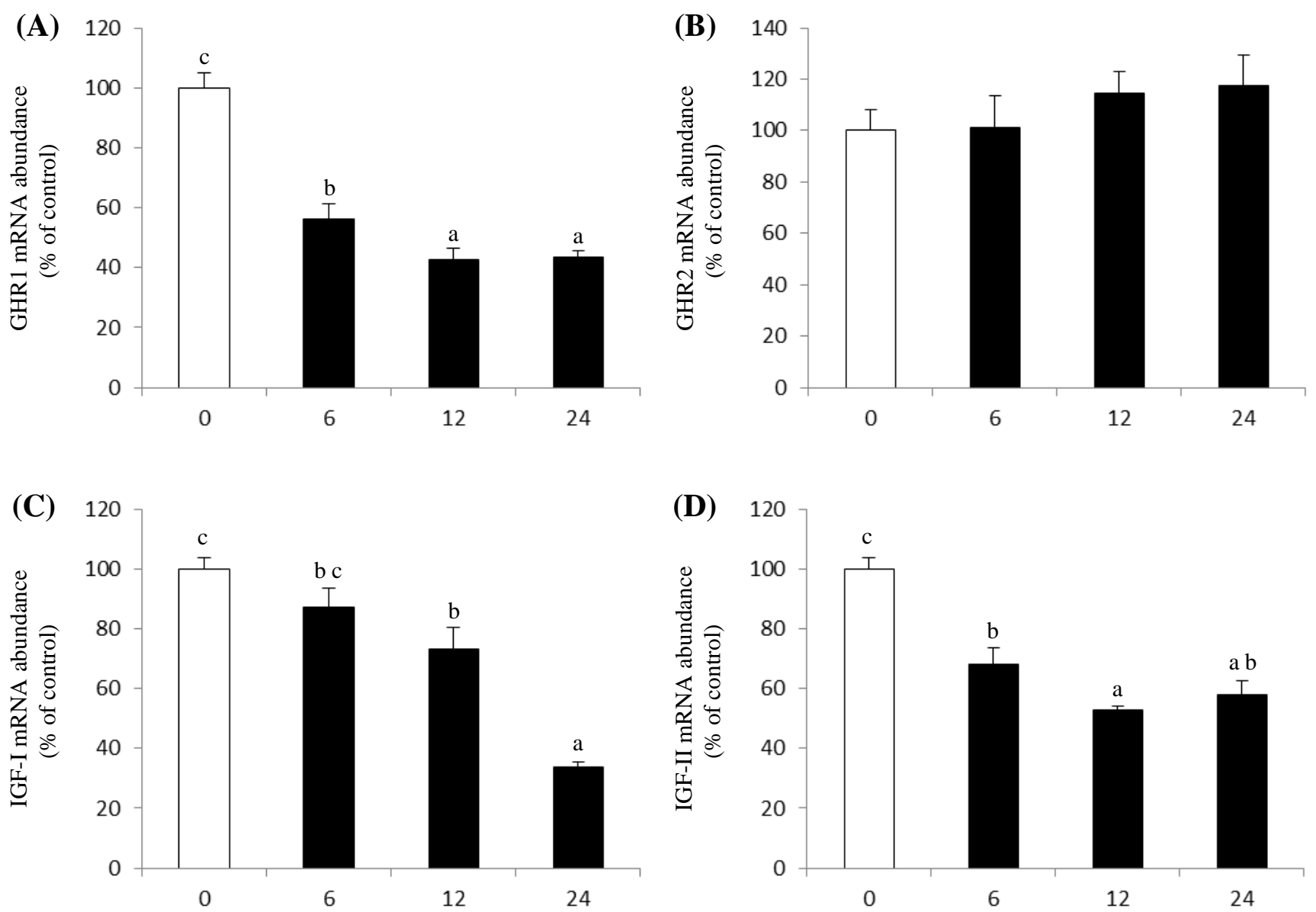

Incubation time $(\mathrm{h})$ 


\section{Figure 4}
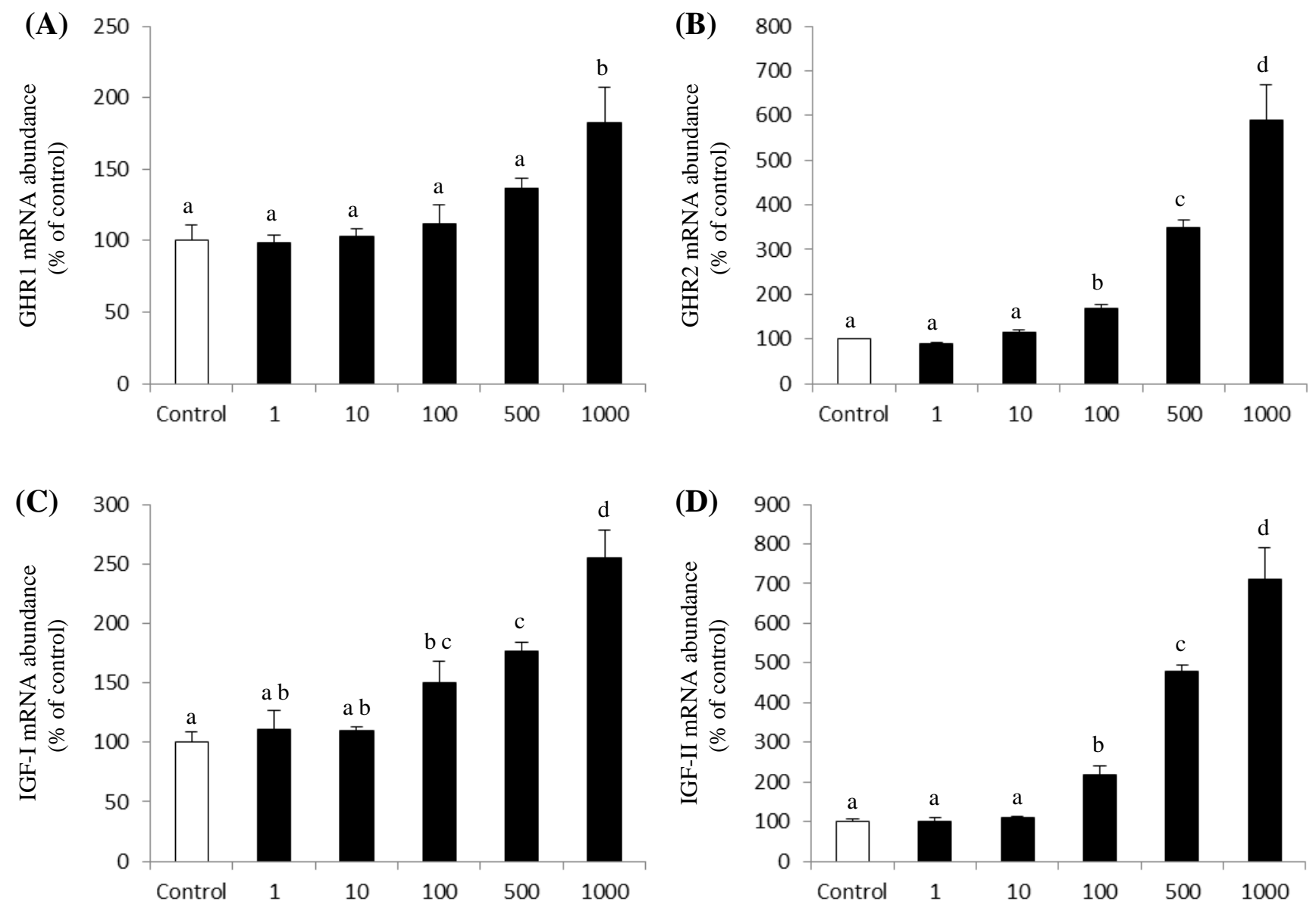

rgGH concentrations $(\mathrm{ng} / \mathrm{mL})$ 


\section{Figure 5}
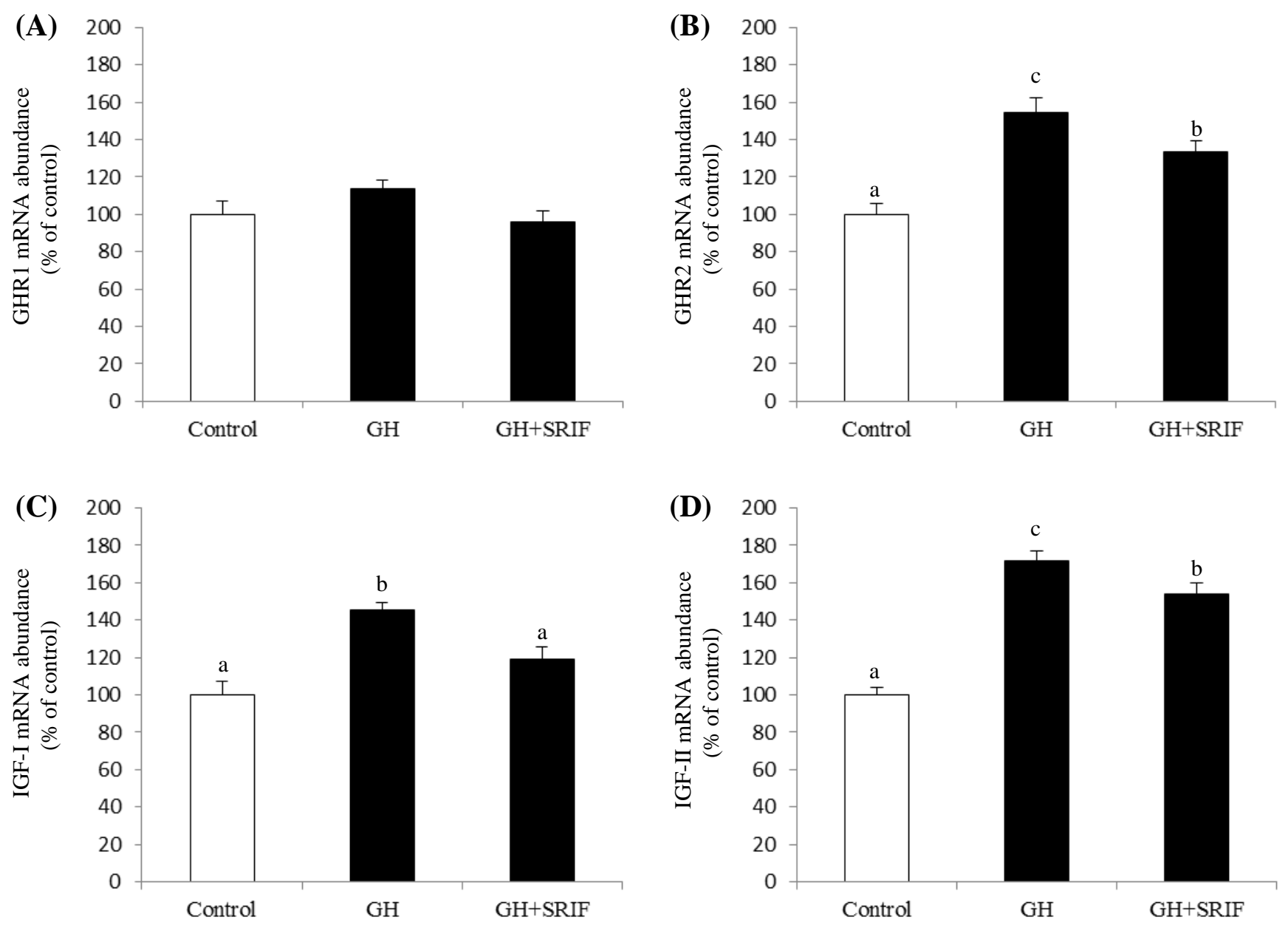